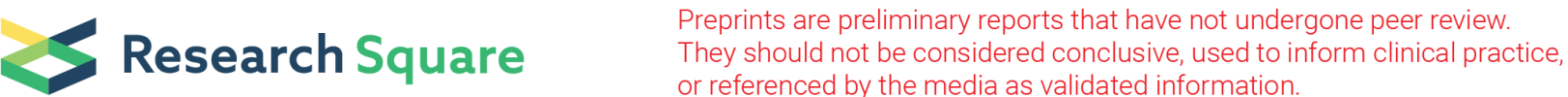

\section{Epidemiological, clinical characteristics of coronavirus-infected disease (COVID-19) among sample of Iranian community: funding from survey in central of Iran}

\section{Marzieh Araban}

Ahvaz Jundishapur University of Medical Sciences

Mahmood Karimy ( $\square$ Karimymahmood@yahoo.com )

Saveh University of medical sciences https://orcid.org/0000-0002-8413-1942

Mehdi Mesri

Baqiyatallah University of Medical Sciences

Bahram Armoon

Saveh University of medical sciences

Hamid Reza Koohestani

Saveh University of medical sciences

Hadi Azani

Saveh University of medical sciences

\section{Research Article}

Keywords: Coronavirus, COVID-19, Epidemiology

Posted Date: June 2nd, 2020

DOI: https://doi.org/10.21203/rs.3.rs-32797/v1

License: (c) (i) This work is licensed under a Creative Commons Attribution 4.0 International License.

Read Full License 


\section{Abstract}

\section{Background}

New Coronavirus disease (COVID-19) is the main pathogens that primarily target the human respiratory organization, represents a public health emergency and global concern. The present study aimed to investigate the epidemiological, clinical characteristics of coronavirus-infected disease (COVID-19) in Saveh city, of Iran, in 2020.

Method

In this descriptive-analytical research, 1142 patients suspected of having coronavirus, participated. Data collection was performed using interviews, inserting information into the researcher-made questionnaires, and using the information in patients' medical records. Data were analyzed by SPSS 21 using Chi-square, independent sample t tests, Fisher's Exact Test, and regression analysis.

Results

multivariate logistic regression models revealed that among clinical symptoms and patents characteristics, some variables were significant predictors of death: Intubation (OR $=8.82 ; 95 \% \mathrm{Cl}$ : (5.1515.63), $\mathrm{PO} 2$ rate $(\mathrm{OR}=2.48 ; 95 \% \mathrm{Cl}$ : $(1.51-4.08)$, Diabetes $(\mathrm{OR}=1.88 ; 95 \% \mathrm{Cl}$ : $(1.00-3.54)$, Shortness of breath $(\mathrm{OR}=1.70 ; 95 \% \mathrm{Cl}:(1.02-2.82)$. Almost half of the patients $(48.3 \%)$ had a history of chronic disease, cardiovascular disease (CVD) (12.8\%), diabetes (11.6\%), and high blood pressure $(9.7 \%)$ were the primary chronic disease among patients.

\section{Conclusion}

Considering the results of the study, designing and implementing targeting and tailoring health education programs for all groups of the community and especially for susceptible people such as elderly and patients with chronic disease, are highly recommended. All in all, risk communication programs regarding COVID-19 might be a priority for responsible agencies.

\section{Background}

Chinese scientists isolated a new Coronavirus (CoV) from patients in Wuhan, China, on January 7 , 2020[1]. The cause of the disease was a new Coronavirus called SARS-CoV-2, and the world health organization (WHO) named the common disease COVID-19, and declared the spread of SARS-CoV-2 as a state of emergency on January 30,2020[2]. The significant number of cases and spread of geographical spread of the disease posed a great threat to public health and attracted considerable attention worldwide[3], so that the World Health Organization declared that new coronavirus infection, COVID-19, as a pandemic (global epidemic) in March 2020[4]. The high rate of virus spread has caused countries to face large numbers of infected people[5]. The current epidemic state of new coronavirus is still severe 
and worrying around the world, and efforts are making to slow its spread to save time to produce the appropriate vaccine or treatment $[5,6]$.

Until two decades ago, human coronaviruses were only known to cause uncomplicated respiratory infections such as cold, but two new coronaviruses, called SARS and MERS (In the years 2003 SARS and 2012 MERS), with higher disease severity, created severe epidemics around the world[7]. Infection with Acute respiratory syndrome COVID-19 is very similar to other viral infections in terms of clinical manifestations $[4,8]$, and patients show a wide range of clinical symptoms from very mild and low symptomatic cases to very severe cases in which patients need intensive care and sometimes lead to death[9]. Fever, cough, and fatigue is the main symptom of the disease at the beginning of COVID-19 infection, while it may be accompanied by other symptoms such as headache, hemoptysis (bloody sputum), diarrhea, shortness of breath sputum, and lymphopenia[9, 10].

In pulmonary CT scans, clear pneumonia is apparent; and RNA of virus can be detected in the blood. In severe cases, the clinical picture of acute shortness of breath syndrome can be observed, and it is associated with heart damage and pulmonary opacification, and usually leads to death. A high percentage of people (about $80 \%$ ) in society show asymptomatic infection or mild symptoms of a cold $[11,12]$. On average, about 20 percent of patients have more severe symptoms of the disease, including pneumonia, sepsis, septic shock, and acute respiratory distress syndrome that is associated with fluid accumulation in the lungs. Based on the severity of the disease, patients need to be assisted in breathing, and a small number of patients die (about $2 \%$ of cases that vary slightly in different studies)[3, 13].

The clinical symptoms of the disease begin after a period of almost 2.5 days, but the incubation period can take up to 14 days. The duration of disease onset until death is from 6 to 41 days and about 14 days on average in severe cases. Its duration depends on several factors, such as the patient's age and status of the immune system, so that the length of this period is shorter in patients over 70 years of age than patients under 70 years of age. People infected with COVID-19 can transmit it to healthy people even a few days before the onset of clinical symptoms $[4,11]$. No specific vaccine or treatment has been offered for the disease yet. The number of cases is rapidly increasing in the current emergency status; hence, it is important to diagnose all suspected cases as soon as possible and isolate them quickly to cut off the infection source[9, 14].

COVID-19 is a new disease that can be transmitted from animals to human; however, there is insufficient knowledge about the new virus and its ways of transmission, zoonotic reservoirs, prevention methods, and its precise clinical manifestations are not entirely clear, and there is a need for further studies. It is necessary to have sufficient information about factors and determinants that are effective in causing its symptoms, complaints of the disease, and its consequences to properly manage this epidemic and take effective preventive and medical coping measures.

\section{Methods}


Chinese scientists isolated a new Coronavirus (CoV) from patients in Wuhan, China, on January 7 , 2020[1]. The cause of the disease was a new Coronavirus called SARS-CoV-2, and the world health organization (WHO) named the common disease COVID-19, and declared the spread of SARS-CoV-2 as a state of emergency on January 30,2020[2]. The significant number of cases and spread of geographical spread of the disease posed a great threat to public health and attracted considerable attention worldwide[3], so that the World Health Organization declared that new coronavirus infection, COVID-19, as a pandemic (global epidemic) in March 2020[4]. Despite the fact that the whole world has taken important steps to curb the spread of COVID-19[15].

The high rate of virus spread has caused countries to face large numbers of infected people[5]. The current epidemic state of new coronavirus is still severe and worrying around the world, and efforts are making to slow its spread to save time to produce the appropriate vaccine or treatment $[5,6]$.

Until two decades ago, human coronaviruses were only known to cause uncomplicated respiratory infections such as cold, but two new coronaviruses, called SARS and MERS (In the years 2003 SARS and 2012 MERS), with higher disease severity, created severe epidemics around the world. Infection with Acute respiratory syndrome COVID-19 is very similar to other viral infections in terms of clinical manifestations $[4,8]$, and patients show a wide range of clinical symptoms from very mild and low symptomatic cases to very severe cases in which patients need intensive care and sometimes lead to death[9]. Fever, cough, and fatigue is the main symptom of the disease at the beginning of COVID-19 infection, while it may be accompanied by other symptoms such as headache, hemoptysis (bloody sputum), diarrhea, shortness of breath sputum, and lymphopenia[9, 10].

In pulmonary CT scans, clear pneumonia is apparent; and RNA of virus can be detected in the blood. In severe cases, the clinical picture of acute shortness of breath syndrome can be observed, and it is associated with heart damage and pulmonary opacification, and usually leads to death. A high percentage of people (about $80 \%$ ) in society show asymptomatic infection or mild symptoms of a cold $[11,12]$. On average, about 20 percent of patients have more severe symptoms of the disease, including pneumonia, sepsis, septic shock, and acute respiratory distress syndrome that is associated with fluid accumulation in the lungs. Based on the severity of the disease, patients need to be assisted in breathing, and a small number of patients die (about $2 \%$ of cases that vary slightly in different studies)[3, 13].

The clinical symptoms of the disease begin after a period of almost 2.5 days, but the incubation period can take up to 14 days. The duration of disease onset until death is from 6 to 41 days and about 14 days on average in severe cases. Its duration depends on several factors, such as the patient's age and status of the immune system, so that the length of this period is shorter in patients over 70 years of age than patients under 70 years of age. People infected with COVID-19 can transmit it to healthy people even a few days before the onset of clinical symptoms $[4,11]$. No specific vaccine or treatment has been offered for the disease yet. The number of cases is rapidly increasing in the current emergency status; hence, it is 
important to diagnose all suspected cases as soon as possible and isolate them quickly to cut off the infection source[9, 14].

COVID-19 is a new disease that can be transmitted from animals to human; however, there is insufficient knowledge about the new virus and its ways of transmission, zoonotic reservoirs, prevention methods, and its precise clinical manifestations are not entirely clear, and there is a need for further studies. It is necessary to have sufficient information about factors and determinants that are effective in causing its symptoms, complaints of the disease, and its consequences to properly manage this epidemic and take effective preventive and medical coping measures.

The present study was descriptive-analytical research in which all 1142 patients suspected of having coronavirus, who visited Saveh Medical Centers from February 9 to April 1 7, 2020, were included in the study. Inclusion criterion: all patients with coronavirus should have filed the hospital. Exclusion criteria: the lack of cooperation and no informed consent to participate in the study. Data collection was performed using interviews, inserting information into the researcher-made questionnaires, and using the information in patients' medical records. To complete the questionnaires about hospitalized patients, the research team visited medical centers after obtaining the necessary permission from the university. In the case of outpatients and patients discharged from the hospital, they were contacted by phone, and then they made an appointment at their houses. After stating the research objectives and obtaining the patients' consent, the researchers interviewed the patients and collected data while maintaining confidentiality. Investigating and collecting the data from patients' files were also with permission from hospital authorities. In the present study, the definitive patients meant to have COVID-19 with positive results of the PCR. A suspected case was a patient with at least one of the following symptoms: dry cough, chills, sore throat, shortness of breath, and fever that were not justified with another etiologic agent. The negative case of the disease had a negative PCR result.

\section{Measures}

The data collection tool of the present study was a researcher-made questionnaire that was designed after reviewing authoritative scientific texts and consulting with experts in infectious diseases and epidemiology. The questionnaire consisted of socio-demographic information (such as age, occupation, gender, occupation, level of education, place of residence) symptoms and risk factors (such as underlying diseases, and history of substance abuse) of COVID-19. The content validity of the questionnaire was determined by both qualitative and quantitative methods. In the qualitative method, the questionnaire was given to 12 professors in the fields of infectious diseases, internal medicine, and epidemiology, and they were asked to examine the questionnaire in terms of using proper words, placement of items in the right places, and compliance with the grammar, and give the feedback. The Content Validity Ratio (CVR) and Content Validity Index (CVI) were calculated in examining the content validity by a quantitative method. To determine the CVR, the experts were asked about the necessity or non-necessity of each item; and values greater than 0.56 were accepted. To determine the CVI, the relevance, clarity, and simplicity of each item were reviewed, and values greater than 0.79 were accepted. 
Data analysis

Data were analyzed by SPSS 21 using Chi-square, independent sample t tests, Fisher's Exact Test, and regression tests. Logistic regression was performed for determining the association between independent variables and death of covid-19. Only those independent variables that showed significant associations with death $(P \leq 0.05)$ in uni-variate analysis were included in the multivariate logistic regression models.

Ethic

Permission to conduct the research was sought, and obtained from the Saveh Medical Centers. This research was approved by the Ethics Committee of Saveh University of Medical Sciences [IR.SAVEHUMS.REC.1399.002].

\section{Results}

The study assessed the data on 1142 patients with suspected COVID-19. The mean age of patients was 52.2 \pm 19.3. Based on the laboratory tests (PCR result), 535 of patients (52.6\%) was positive for COVID-19, $483(42.2 \%)$ negative, and $124(10.8 \%)$ of patients died. The mean age for COVID-19 patients(PCR+) was $56.9 \pm 17.3$. The age ranges of $46-55$ had a higher rate of mortality (i.e. $20.2 \%$ ). The mean duration of hospitalization was $6.5 \pm 8.5$ days. Of Covid-19 positive patients, $282(58 \%)$ were men. Of whom, $144(29.8 \%)$ reported a history of contact with COVID-19 patients. Ten percent of all patients (either positive or negative) reported a history of contact with COVID-19 patients. Ten percent (114) of patients were taken to the hospital by emergency medical personnel. The results presented in Table 1, showed that there were significant differences between Covid-19 positive and negative patients in terms of age, sex, a history of contact with COVID-19 patient, and the duration of hospitalization $(P<0.05)$. Almost half of the patients (48.3\%) had a history of chronic disease, cardiovascular disease (CVD) (12.8\%), diabetes (11.6\%), and high blood pressure (9.7) were the primary chronic disease among patients. The results are presented in Table 2. The symptoms in hospital arrival time were as follows: cough (44.5\%), fever $(41.8 \%)$, shortness of breath $(40.1 \%)$. The rate of PO2 saturation in $183(38.3 \%)$ was less than $93,34(7 \%)$ need intubation, and 16 (3.3\%) had positive signs in CT scan (Table 3 ).

Out of 124 deaths, 75 patients were positive for COVID-19. The mean age of died patients was 69.5 \pm 15.7 , and the duration of hospitalization was 7.2 days. The age ranges of 76-85 had the higher rate of mortality. Of patients with COVID-19 positive test, more than half $(70.6 \%)$ were men.

In total, of patients who died, $54.6 \%$ had a history of chronic disease. Of which, CVD, DM, HTN, were the most common diseases (22.6ه22.6 10.6\% between patients who died and who did not in regard to COPD, table 2 . The other comparisons between patients with covid-19 who died and who did not have been reported in table 3 . The results of multivariate logistic regression models revealed that among clinical symptoms and patients' characteristics, some variables were significant predictors of death: Intubation $(\mathrm{OR}=8.82 ; 95 \% \mathrm{Cl}$ : $(5.15-15.63) \otimes \mathrm{PO} 2$ rate $(\mathrm{OR}=$ 
2.48; $95 \% \mathrm{Cl}:(1.51-4.08) \otimes$ Diabetes $(\mathrm{OR}=1.88 ; 95 \% \mathrm{Cl}:(1.00-3.54)$, Shortness of breath $(\mathrm{OR}=1.70 ; 95 \%$ Cl: (1.02-2.82) (table 4).

\section{Discussion}

This study assessed the epidemiology and risk factors of COVID-19 and its outcomes in Saveh, Iran. The age ranges for COVID-19 were 16-86 with a wide range of symptoms, including cough, fever, and respiratory symptoms. In this study, the mean age of patients with COVID-19 was 56 years, which was seven years more than that of an earlier study by Huang et al., study. One possible explanation for such a difference might be due to the different use of corona virus.

In this study, most of the patients were men and the mortality rate was higher among the men. This is consistent with earlier studies. Also, some biologic differences between men and women might justify the difference, as confirmed by an earlier report[16]. Also, this report revealed that CVD and long disease are more prevalent among men.

In this study, mortality increased both in patients with advancing age, which is in line with earlier studies[13,17], and inpatient with patients with a history of chronic diseases, which is consistent with earlier studies $[4,18]$. These findings highlighted the importance of notice to susceptible groups such as the elderly and patients with a history of chronic diseases. Therefore, establishing a tailored prevention approach for these groups is of critical importance.

Most of the patients did not report a history of contact with COVID-19 positive patients. Since the virus mainly spread through contact with infected people, contact with infected people during the incubation period might infect the people. Therefore, adopting preventive strategies[13] such as wearing face masks and washing hands should be educative at population levels. Also, launching campaigns should be on the agenda of authorities. However, it proved that isolation and effective contact tracing is necessary to control an epidemic of COVID-19[19].

In this study, the mortality rate was equal to 10.3 percent, which was greater than those of previous studies i.e. $2.58 \%$ for age ranges of $48-89$ years[13] and 2.3 for the age ranges of $48-89$ years[20]. Only CT findings of 7 percent were positive for COVID-19, which is far from another study from China; the study from China found all patient positive for COVID-19. In this regard, one might conclude that the CT scan operators need more education for the diagnosis of COVID-19.

\section{Conclusion}

Patients with Covid-19 had a wide range of symptoms. Only a few percent's needed hospitalization in ICU. Most of the patients had at least one underlying disease. The duration of hospitalization ranged from 7-10 days. Considering the results of the study, designing and implementing targeting and tailoring health education programs for all groups of the community and especially for susceptible people such as 
elderly and patients with chronic disease, are highly recommended. All in all, risk communication programs regarding COVID-19 might be a priority for responsible agencies.

\section{Abbreviations}

CVD: Cardiovascular diseases

MERS: Middle East respiratory syndrome

SARS: Search Results

SARS: Severe Acute Respiratory Syndrome

HTN: Hypertension

CVl: Content Validity Index

CVR: Content Validity Rate

\section{Declarations}

\section{Acknowledgments}

We would like to thank all patients who participated in this study, the authors are grateful to the Vice Saveh University of Medical Sciences for their assistance with study implementation.

\section{Authors' contributions}

MK conceived the study. BA, HA, MA, HRK, MK and MM designed the study, collected the data, interpreted the results, contributed to writing the Article, and approved the final version for submission.

Funding No financial support was received for this research.

\section{Availability of data and materials}

Upon request, we can offer onsite access to external researchers to the data analyzed at Saveh University of Medical Sciences, Saveh, Iran. To do so, Dr. karimy should be contacted.

\section{Funding source}

None.

\section{Ethics approval and consent to participate}

Permission to conduct the research was sought, and obtained from the Saveh Medical Centers. This research was approved by the Ethics Committee of Saveh University of Medical Sciences 
[IR.SAVEHUMS.REC.1399.002].

\section{Consent for publication Not applicable.}

Competing interests The authors declare that they have no competing interests.

\section{References}

1. Li, J.-Y., et al., The epidemic of 2019-novel-coronavirus (2019-nCoV) pneumonia and insights for emerging infectious diseases in the future. Microbes and Infection, 2020. 22(2): p. 80-85.

2. Poon, L.L. and M. Peiris, Emergence of a novel human coronavirus threatening human health. Nature medicine, 2020. 26(3): p. 317-319.

3. Bastola, A., et al., The first 2019 novel coronavirus case in Nepal. The Lancet Infectious Diseases, 2020. 20(3): p. 279-280.

4. Chen, N., et al., Epidemiological and clinical characteristics of 99 cases of 2019 novel coronavirus pneumonia in Wuhan, China: a descriptive study. The Lancet, 2020. 395(10223): p. 507-513.

5. Chen, S., et al., COVID-19 control in China during mass population movements at New Year. The Lancet, 2020. 395(10226): p. 764-766.

6. Bai, Y., et al., Presumed asymptomatic carrier transmission of COVID-19. Jama, 2020. 323(14): p. 1406-1407.

7. Wang, Y., et al., Lack of association between polymorphisms of MASP2and susceptibility to SARS coronavirus infection. BMC Infectious Diseases, 2009. 9(1): p. 51.

8. Peeri, N.C., et al., The SARS, MERS and novel coronavirus (COVID-19) epidemics, the newest and biggest global health threats: what lessons have we learned? International journal of epidemiology, 2020.

9. Sohrabi, C., et al., World Health Organization declares global emergency: A review of the 2019 novel coronavirus (COVID-19). International Journal of Surgery, 2020.

10. Pan, F., et al., Time course of lung changes on chest CT during recovery from 2019 novel coronavirus (COVID-19) pneumonia. Radiology, 2020: p. 200370.

11. Shi, H., et al., Radiological findings from 81 patients with COVID-19 pneumonia in Wuhan, China: a descriptive study. The Lancet Infectious Diseases, 2020.

12. Yee, J., et al., Novel coronavirus 2019 (COVID-19): Emergence and implications for emergency care. Journal of the American College of Emergency Physicians Open, 2020.

13. Rothan, H.A. and S.N. Byrareddy, The epidemiology and pathogenesis of coronavirus disease (COVID19) outbreak. Journal of autoimmunity, 2020: p. 102433.

14. Xu, G., et al., Clinical Pathway for Early Diagnosis of COVID-19: Updates from Experience to EvidenceBased Practice. Clinical Reviews in Allergy \& Immunology, 2020: p. 1-12. 
15. Zhang, S., et al., Estimation of the reproductive number of novel coronavirus (COVID-19) and the probable outbreak size on the Diamond Princess cruise ship: a data-driven analysis. International Journal of Infectious Diseases, 2020. 93: p. 201-204.

16. The, L., Palliative care and the COVID-19 pandemic. The Lancet, 2020. 395(10231): p. 1168.

17. Wang, W., J. Tang, and F. Wei, Updated understanding of the outbreak of 2019 novel coronavirus (2019-nCoV) in Wuhan, China. Journal of medical virology, 2020. 92(4): p. 441-447.

18. Li, Q., et al., Early transmission dynamics in Wuhan, China, of novel coronavirus-infected pneumonia. New England Journal of Medicine, 2020.

19. Hellewell, J., et al., Feasibility of controlling COVID-19 outbreaks by isolation of cases and contacts. The Lancet Global Health, 2020.

20. Surveillances, V., The epidemiological characteristics of an outbreak of 2019 novel coronavirus diseases (COVID-19)-China, 2020. China CDC Weekly, 2020. 2(8): p. 113-122.

21. Kawyannejad, R., et al., General health of students of medical sciences and its relation to sleep quality, cell phone overuse, social networks and internet addiction. 2019. 13(1): p. 12.

\section{Tables}

Table 1. Absolute and relative frequency distribution of demographic variables of patients

\begin{tabular}{|c|c|c|c|c|c|c|}
\hline \multirow[b]{2}{*}{ Variable } & \multicolumn{2}{|c|}{ death } & \multirow[b]{2}{*}{$\mathrm{P} \mathrm{a}$} & \multicolumn{2}{|c|}{ patient } & \multirow[b]{2}{*}{$\mathrm{P}$} \\
\hline & Positive & negative & & positive & negative & \\
\hline & {$[\mathrm{N}[21$} & {$[\mathrm{N}[21$} & & {$[\mathrm{N}[21$} & {$[\mathrm{N}[21$} & \\
\hline & (65) 75 & (35)39 & & $(47) 483$ & (53)535 & \\
\hline \multicolumn{7}{|l|}{ Age } \\
\hline $1-15$ & 0 & 0 & \multirow[t]{9}{*}{0.02} & 0 & 8 & \multirow[t]{9}{*}{$0.001^{\mathrm{a}}$} \\
\hline $16-25$ & (1.7)2 & (0.9)1 & & (11.7)12 & (38)39 & \\
\hline $26-35$ & (3.5) 4 & (1.7)2 & & $(42.2) 43$ & (14.8)151 & \\
\hline $36-45$ & (6) 7 & $(2.6) 3$ & & (7.8)80 & (12.3)125 & \\
\hline $46-55$ & 0 & (8.7)10 & & (9.6) 98 & (6.2)67 & \\
\hline 56-65 & (2.6)3 & (9.6) 11 & & (9.2)94 & $(4.5) 46$ & \\
\hline $66-75$ & $(5.2) 6$ & $(10.5) 12$ & & (6.9) 71 & (3.7)38 & \\
\hline $76-85$ & $(10.5) 12$ & (22.8)26 & & (5.8) 60 & (3)31 & \\
\hline $86 \leq$ & (4.3)5 & (8.7) 10 & & (2.4) 25 & (2.3) 24 & \\
\hline Mean \pm SD & $69.5 \pm 15.7$ & $64.0 \pm 22.3$ & 0.132 & $56.9 \pm 17.3$ & $45.6 \pm 19.2$ & $0.001^{\mathrm{b}}$ \\
\hline \multicolumn{7}{|l|}{ Gender } \\
\hline Men & $(46.4) 53$ & (11.4)13 & \multirow[t]{2}{*}{0.001} & (27.7)282 & (20.3)207 & \multirow[t]{2}{*}{$0.001^{c}$} \\
\hline Women & (19.2)22 & $(22.8) 26$ & & (19.7)201 & $(32.2) 328$ & \\
\hline \multicolumn{7}{|l|}{ Contact with COVID 19 patient } \\
\hline Yes & (6) 7 & (22.8)26 & \multirow[t]{2}{*}{0.08} & $(14.1) 144$ & (29)296 & \multirow[t]{2}{*}{$0.001^{\mathrm{C}}$} \\
\hline No & (28) 32 & $(42.9) 49$ & & (33.3)339 & $(23.4) 239$ & \\
\hline \multicolumn{7}{|l|}{ Duration of hospitalization } \\
\hline Mean \pm SD & $7.2 \pm 5.7$ & $9.8 \pm 15.4$ & 0.219 & $6.5 \pm 8.5$ & $3.5 \pm 8.1$ & $0.001^{\mathrm{b}}$ \\
\hline
\end{tabular}

a Chi-square b T-test c Fisher's Exact Test 
Table 2. Absolute and relative frequency distribution of underlying diseases of patients

\begin{tabular}{|c|c|c|c|c|c|c|}
\hline \multirow[b]{2}{*}{ Variable } & \multicolumn{2}{|c|}{ death } & \multirow[b]{2}{*}{$\mathrm{P} \mathrm{a}$} & \multicolumn{2}{|c|}{ patient } & \multirow[b]{2}{*}{${ }_{a} \mathrm{P}$} \\
\hline & positive & negative & & positive & negative & \\
\hline & {$[\mathrm{N}[21$} & {$[\mathrm{N}[21$} & & {$[\mathrm{N}[21$} & {$[\mathrm{N}[21$} & \\
\hline & (65)75 & (35)39 & & (47)483 & (53)535 & \\
\hline \multicolumn{7}{|l|}{ Cancer } \\
\hline Yes & $(0) 0$ & (1.7)2 & \multirow[t]{2}{*}{0.115} & $(0.29) 3$ & $(0.58) 6$ & \multirow[t]{2}{*}{0.511} \\
\hline No & (65)75 & (33.3)37 & & $(47.1) 480$ & (51.9) 529 & \\
\hline \multicolumn{7}{|l|}{ Hypertension } \\
\hline Yes & (7)8 & (5.3)6 & \multirow[t]{2}{*}{0.551} & (4.6) 47 & (3.8)39 & \multirow[t]{2}{*}{0.162} \\
\hline No & (59)67 & (29)33 & & $(42.8) 436$ & $(48.7) 496$ & \\
\hline \multicolumn{7}{|l|}{ Diabetes } \\
\hline Yes & $(11.4) 13$ & (7) 8 & \multirow[t]{2}{*}{0.431} & (5.5)56 & (4.3) 44 & \multirow[t]{2}{*}{0.04} \\
\hline No & $(54.3) 62$ & $(27.2) 31$ & & (41.9)427 & $(48.2) 491$ & \\
\hline \multicolumn{7}{|l|}{ Heart disease } \\
\hline Yes & (14.9)17 & $(4.3) 5$ & \multirow[t]{2}{*}{0.317} & (6.1)62 & (4.3) 44 & \multirow[t]{2}{*}{0.01} \\
\hline No & $(50.8) 58$ & $(29.8) 34$ & & (41.3)421 & $(48.2) 491$ & \\
\hline \multicolumn{7}{|l|}{ COPD } \\
\hline Yes & $(0.9) 1$ & $(5.2) 6$ & \multirow[t]{2}{*}{0.006} & (1) 11 & $(0.49) 5$ & \multirow[t]{2}{*}{0.128} \\
\hline No & (65)74 & (29) 33 & & $(46.3) 472$ & (52)530 & \\
\hline \multicolumn{7}{|l|}{ Asthma } \\
\hline Yes & (0.9)1 & $(0.9) 1$ & \multirow[t]{2}{*}{0.569} & $(0.58) 6$ & (1)11 & \multirow[t]{2}{*}{0.339} \\
\hline No & (65)74 & (34)38 & & $(46.8) 477$ & $(51.4) 524$ & \\
\hline \multicolumn{7}{|l|}{ Renal disease } \\
\hline Yes & $(1.7) 2$ & (1.7)2 & \multirow[t]{2}{*}{0.605} & (1) 11 & $(0.88) 9$ & \multirow[t]{2}{*}{0.508} \\
\hline No & (64)73 & $(32.4) 37$ & & (46) 472 & (51.6)526 & \\
\hline \multicolumn{7}{|l|}{ Liver disease } \\
\hline Yes & 0 & 0 & \multirow[t]{2}{*}{-} & $(0.09) 1$ & $(0.19) 2$ & \multirow[t]{2}{*}{0.538} \\
\hline No & (65)75 & (35)39 & & $(47.3) 482$ & (52.5)535 & \\
\hline \multicolumn{7}{|l|}{ Hematologic disease } \\
\hline Yes & $(1.7) 2$ & $(0.9) 1$ & 0.731 & $(0.49) 5$ & $(0.58) 6$ & 0.569 \\
\hline No & (64)73 & (34)38 & & (47)478 & (52)529 & \\
\hline
\end{tabular}

a Fisher's Exact Test

Table 3. Absolute and relative frequency distribution of common symptoms of patients 


\begin{tabular}{|c|c|c|c|c|c|c|}
\hline \multirow[b]{2}{*}{ Variable } & \multicolumn{2}{|c|}{ death } & \multirow[b]{2}{*}{$\mathrm{P}$ a } & \multicolumn{2}{|c|}{ patient } & \multirow[b]{2}{*}{$\mathrm{Pa}$} \\
\hline & positive & negative & & positive & negative & \\
\hline & {$[\mathrm{N}[21$} & {$[\mathrm{N}[21$} & & {$[\mathrm{N}[21$} & {$[\mathrm{N}[21$} & \\
\hline & (65) 75 & (35)39 & & $(47) 483$ & (53)535 & \\
\hline \multicolumn{7}{|l|}{ CT scan manifestation } \\
\hline Yes & (7) 8 & $(5.2) 6$ & \multirow[t]{2}{*}{0.467} & (1.5) 16 & (1.6)17 & \multirow[t]{2}{*}{0.521} \\
\hline No & $(58.7) 67$ & (29)33 & & $(45.8) 467$ & $(50.8) 518$ & \\
\hline \multicolumn{7}{|l|}{ Loss of consciousness } \\
\hline Yes & $(4.3) 5$ & (4.3) 5 & \multirow[t]{2}{*}{0.306} & $(0.58) 6$ & $(0.98) 10$ & \multirow[t]{2}{*}{0.461} \\
\hline No & $(61.4) 70$ & $(29.8) 34$ & & $(46.8) 477$ & $(51.5) 525$ & \\
\hline \multicolumn{7}{|l|}{ Intubation } \\
\hline Yes & $(28) 32$ & $(19.2) 22$ & \multirow[t]{2}{*}{0.173} & (3.3)34 & $(2.2) 23$ & \multirow[t]{2}{*}{0.05} \\
\hline No & $(37.7) 43$ & (14.9)17 & & $(44.1) 449$ & $(50.3) 512$ & \\
\hline \multicolumn{7}{|l|}{ Po2 } \\
\hline $93<$ & (21.9)25 & (6) 7 & \multirow[t]{2}{*}{0.123} & $(29.2) 298$ & $(41.0) 418$ & \multirow[t]{2}{*}{0.001} \\
\hline $93>$ & $(43.8) 50$ & (28) 32 & & (18.1)185 & $(11.4) 117$ & \\
\hline \multicolumn{7}{|l|}{ Fever } \\
\hline Yes & $(24.5) 28$ & $(5.2) 6$ & \multirow[t]{2}{*}{0.01} & (19.8)202 & $(10.3) 105$ & \multirow[t]{2}{*}{0.001} \\
\hline No & $(41.2) 47$ & $(28.9) 33$ & & (27.6)281 & $(42.2) 430$ & \\
\hline \multicolumn{7}{|l|}{ Cough } \\
\hline Yes & $(20.1) 23$ & (3.5) 4 & \multirow[t]{2}{*}{0.01} & $(21.1) 215$ & $(12.8) 131$ & \multirow[t]{2}{*}{0.001} \\
\hline No & $(45.6) 52$ & $(30.7) 35$ & & $(26.3) 268$ & $(39.6) 404$ & \\
\hline \multicolumn{7}{|l|}{$\begin{array}{r}\text { myalgia or } \\
\text { fatigue }\end{array}$} \\
\hline Yes & $(8.7) 10$ & $(2.6) 3$ & \multirow[t]{2}{*}{0.537} & $(10.2) 104$ & (6) 62 & \multirow[t]{2}{*}{0.001} \\
\hline No & $(57) 65$ & $(31.5) 36$ & & $(37.2) 379$ & $(46.4) 473$ & \\
\hline \multicolumn{7}{|l|}{ Shortness of breath } \\
\hline Yes & $(30.7) 35$ & (.19) 22 & \multirow[t]{2}{*}{0.430} & (19)194 & $(10.7) 109$ & \multirow[t]{2}{*}{0.001} \\
\hline No & $(35) 40$ & $(14.9) 17$ & & $(28.3) 289$ & $(41.8) 426$ & \\
\hline \multicolumn{7}{|l|}{ gastrointestinal disorders } \\
\hline Yes & $(1.7) 2$ & $(0.9) 1$ & 0.731 & $(0.68) 7$ & $(0.88) 9$ & 0.483 \\
\hline No & $(64) 73$ & (34)38 & & $(46.7) 476$ & $(51.6) 526$ & \\
\hline
\end{tabular}

a Fisher's Exact Test

Table 4. Results of the multivariate logistic regression analysis of factors associated with death 


\begin{tabular}{|c|c|c|c|c|c|c|c|}
\hline \multirow[t]{2}{*}{ variables } & \multirow[t]{2}{*}{ B } & \multirow[t]{2}{*}{ Std. Error } & \multirow[t]{2}{*}{ Wald } & \multirow[t]{2}{*}{ Sig. } & \multirow[t]{2}{*}{$\operatorname{Exp(B)}$} & \multicolumn{2}{|c|}{$\begin{array}{l}\text { 95\% Confidence } \\
\text { Interval for } \operatorname{Exp}(\mathrm{B})\end{array}$} \\
\hline & & & & & & Lower & Upper \\
\hline \multicolumn{8}{|l|}{ Loss of consciousness } \\
\hline No & Ref. & & & & Ref. & & \\
\hline yes & 0.976 & 0.623 & 2.45 & 0.117 & 2.65 & 0.782 & 9.00 \\
\hline \multicolumn{8}{|l|}{ Intubation } \\
\hline No & Ref. & & & & Ref. & & \\
\hline yes & 2.19 & 0.28 & 60.12 & 0.001 & 8.97 & 5.15 & 15.63 \\
\hline \multicolumn{8}{|l|}{ Po2 } \\
\hline$>93$ & Ref. & & & & Ref. & & \\
\hline $93>$ & 0.911 & 0.253 & 12.96 & 0.001 & 2.48 & 1.51 & 4.08 \\
\hline \multicolumn{8}{|l|}{ Cough } \\
\hline No & Ref. & & & & Ref. & & \\
\hline yes & 0.461 & 0.271 & 2.88 & 0.08 & 1.58 & 0.932 & 2.69 \\
\hline \multicolumn{8}{|l|}{ Weakness and body aches } \\
\hline No & Ref. & & & & Ref. & & \\
\hline yes & 0.397 & 0.365 & 1.18 & 0.277 & 1.48 & 0.727 & 3.04 \\
\hline \multicolumn{8}{|l|}{ Shortness of breath } \\
\hline No & Ref. & & & & Ref. & & \\
\hline yes & 0.532 & 0.259 & 4.20 & 0.04 & 1.70 & 1.02 & 2.82 \\
\hline \multicolumn{8}{|l|}{ Hypertension } \\
\hline No & Ref. & & & & Ref. & & \\
\hline yes & 0.667 & 0.652 & 1.04 & 0.306 & 1.94 & 0.543 & 6.99 \\
\hline \multicolumn{8}{|l|}{ Diabetes } \\
\hline No & Ref. & & & & Ref. & & \\
\hline yes & 0.632 & 0.323 & 3.83 & 0.05 & 1.88 & 1.00 & 3.54 \\
\hline
\end{tabular}

